\title{
Investigation of the Behaviour of Volterra Integral Equations with Random Effects
}

\author{
Volterra İntegral Denklemlerinin Rastgele Etkilerle Davranışlarının İncelenmesi
}

\author{
Mehmet MERDAN*1,a ${ }^{\text {, }}$ zge ALTAY ${ }^{1, b}$, Zafer BEKİRYAZICI $^{2, c}$ \\ ${ }^{I}$ Department of Mathematical Engineering, Gümüşhane University, Gümüşane, Turkey \\ ${ }^{2}$ Department of Mathematics, Recep Tayyip Erdoğan University, Rize, Turkey
}

• Geliş tarihi / Received: 04.07.2019 ～• Düzeltilerek geliş tarihi / Received in revised form: 15.11.2019 Kabul tarihi / Accepted: 20.11.2019

\begin{abstract}
In this study, random Volterra integral equations obtained by transforming components of deterministic Volterra integral equations to random variables are analysed. Beta, Normal (Gaussian), Gamma, Geometric and Uniform distributions are used to investigate the random behaviour of the solutions for Volterra integral equations under random effects. The random version of Differential Transformation Method (RDTM) is used to obtain an approximation to the solution of the random Volterra integral equation. Using the approximate solutions, approximate expected values and approximate variances are calculated. Some integro-differential equations, obtained by using random components with the above mentioned distributions, are solved as numerical examples. Results are obtained in MAPLE and shown in graphs. It is seen that random Differential Transformation Method is effective for the examination of random Volterra integral equations. Comparison of the solutions is given to underline the accuracy of the method.

Keywords: Differential Transformation Method, Expected Value, Modified DTM, Variance, Volterra Integral Equation

$\ddot{O} z$

Bu çalışmada deterministik Volterra integral denklemlerinin bileşenlerinin rastgele değişkenlere dönüştürülmesi ile elde edilen rastgele Volterra integral denklemleri incelenmektedir. Volterra integral denklemlerinin rastgele etkiler altındaki rastgele davranışlarını incelemek için Beta, Normal, Gamma, Geometrik ve Düzgün dağgllımlar kullanılmaktadır. Rastgele Volterra integral denkleminin çözümüne bir yaklaşım elde etmek için Diferansiyel Dönüşüm Yöntemi'nin rastgele versiyonu (RDTM) kullanılmaktadır. Yaklaşık çözüm kullanılarak yaklaşık beklenen değerler ve yaklaşık varyanslar hesaplanmaktadır. Bahsedilen dağılımlara sahip rastgele bileşenler kullanılarak elde edilen bazı integro-diferansiyel denklemler sayısal örnek olarak kullanılmaktadır. Sonuçlar MAPLE'da elde edilmiş ve grafiklerle gösterilmişstir. Rastgele Diferansiyel Dönüşüm Yöntemi'nin rastgele Volterra İntegral Denklemleri'nin incelenmesinde etkili bir araç olduğu görülmektedir. Yöntemin doğruluğunu göstermek için sonuçların karşılaştırmalarına yer verilmişstir.
\end{abstract}

Keywords: Diferansiyel Dönüşüm Yöntemi, Beklenen Değer, Modifiye DTM, Varyans, Volterra İntegral Denklemi

\footnotetext{
$*^{\mathrm{a}}$ Mehmet MERDAN; mmerdan@ gumushane.edu.tr, orcid.org/0000-0002-8509-3044

${ }^{\mathrm{b}}$ orcid.org/0000-0003-2134-4059 ${ }^{\mathrm{c}}$ orcid.org/0000-0001-5671-9995
} 


\section{Introduction}

Integral equations are used in a various area of science. Many problems in a wide range of fields can be analysed by using integral equations, since some of the problems defined by differential equations with initial or boundary values can be converted to integral equations. Problems in biology, geophysics, economics and radiation are only some of the areas where integral equations are used. It is also known that potential theory is an important area for the literature of the application of integral equations. Since there is an extensive field of applications for these equations, their computational analysis is a widely studied research subject (Wazwaz, 2011; Kythe and Puri, 2011). In this regard, the Volterra equation is one of the essential types of integral equations.

The use of ordinary, partial and various other types of differential equations, as mentioned above, play an important role in the modelling of various real-life phenomena. However, the deterministic versions of these equations sometimes fall short in reflecting the actual course of events accurately. Hence, the use of random components within differential equations to model the randomness of the systems under investigation within the equations has been attracting interest. Random differential equations obtained by using random variables as the coefficients, initial values or inhomogenous parts of deterministic differential equations have been used for applications in many areas such as biology, medicine and engineering (Chiles and Delfier, 1999; Cortes et al., 2009; Soong, 1973). The use of mean-square calculus base methods for various random equations systems have become an important area of mathematical modelling (Cortes et al, 2009; Cortes et al, 2007a, Cortes et al, 2007b; Villafuerte et al., 2010; Calbo et al., 2010; Cortes et al., 2010; Cortes et al., 2011; Khudair, 2016). While there are many random systems in the literature, many of these models are too complex to be solved analytically. Hence, approximation schemes are preferred in studies to analyse these systems. George Adomian's approximation technique Adomian Decomposition Method (ADM) (Cherrault et al., 1993), He's Variational Iteration Method (VIM) (Khudair et al, 2011) and also the Homotopy Perturbation Method (HPM) (Khalaf, 2011) are among some of the widely used method in this sense. Many other methods and applications can be found in the literature (Khudair et al, 2016; Kuhdair et al, 2011, Khalaf, 2011; Merdan et al., 2019).

In this study, we will be following a similar approach to the above-mentioned literature on random differential equation systems. Components of Volterra integral equations will be transformed into random variables with several probability distributions. Random Differential Transform Method (RDTM) will be applied to find the exact or approximate solutions of the given Volterra integral equations with random components. Using the approximate solutions obtained with RDTM, the approximate expected values and variances of the random Volterra integral equations will be given along with their graphs. Sections 2 and 3 include introductory information on Volterra integral equations and Differential Transformation Method. In section 5, several numerical examples are given with uniform, beta, normal, gamma and geometric distributions, respectively.

\section{Fredholm and Volterra integral equations}

The linear Fredholm integral equation is given as

$$
\varphi(x) u(x)=f(x)+\lambda \int_{a}^{b} K(x, t) u(t) d t
$$

where the integration is done between the upper limit $a$ and the lower limit $b$ and the unknown function $u(x)$ is within the integration linearly. For $\varphi(x)=1$, the equation (1) simplifies to

$$
u(x)=f(x)+\lambda \int_{a}^{b} K(x, t) u(t) d t
$$

which is known as the Fredholm integral equation of the second kind. For the case where $\varphi(x)=0$, the equation (1) becomes

$$
f(x)+\lambda \int_{a}^{b} K(x, t) u(t) d t=0
$$


which is known as the Fredholm integral equation of the first kind. When the unknown function within the integration is in functional form $F(u(x))$ with the power of the function different than one, i.e. $F(u(x))=$ $u^{n}(x), n \neq 1$, or equal to $\sin u(x)$, etc., the integral equations (Fredholm or Volterra) are said to be nonlinear (Lovitt, 1950; Wazwaz, 1997; Wazwaz, 1999; Mohyud-Din et al., 2010, Arikoglu and Ozkol, 2005; Arikoglu and Ozkol, 2008). The Volterra integral equations (of first and second kind) are also given as follows(Aksoy, 1983):

$$
\begin{aligned}
& \Phi(x)=\int_{a}^{x} K(x, t) u(t) d t \\
& u(x)=\int_{a}^{x} K(x, t) u(t) d t \\
& u(x)=f(x)+\int_{a}^{x} K(x, t) u(t) d t \\
& \Phi(x) u(x)=f(x)+\int_{a}^{x} K(x, t) u(t) d t
\end{aligned}
$$

\section{Differential transform method}

For the Differential Transformation Method of a function with one variable, the transformation of the k-th derivative for a function is given as

$$
F(k)=\frac{1}{k !}\left[\frac{d^{k} f(x)}{d x^{k}}\right]_{x=x_{0}},
$$

whereas the inverse transformation is given as

$$
f(x)=\sum_{k=0}^{\infty} F(k)\left(x-x_{0}\right)^{k}
$$

The theorems below are obtained by using (4) and (5):

Theorem 1: If $f(x)=g(x) \pm h(x)$, then $F(k)=G(k) \pm H(k)$.

Theorem 2: If $f(x)=c g(x)$, then $F(k)=c G(k)$, where $c$ is a constant.

Theorem 3: If $f(x)=\frac{d^{n} g(x)}{d x^{n}}$, then $F(k)=\frac{(k+n) !}{k !} G(k+n)$.

Theorem 4: If $f(x)=g(x) h(x)$, then $F(k)=\sum_{k_{1}=0}^{k} G\left(k_{1}\right) H\left(k-k_{1}\right)$.

Theorem 5: If $f(x)=x^{n}$, then $F(k)=\delta(k-n)$ where, $\delta(k-n)=\left\{\begin{array}{l}1, k=n \\ 0, k \neq n\end{array}\right.$.

Theorem 6 (Arikoglu and Ozkol, 2008; Fakharzadeh et al., 2015): If $f(x)=g_{1}(x) g_{2}(x) \ldots g_{n-1}(x) g_{n}(x)$, then $F(k)=\sum_{k_{n-1=0}}^{k} \sum_{k_{n-2}=0}^{k_{n-1}} \cdots \sum_{k_{2}=0}^{k_{3}} \sum_{k_{1}=0}^{k_{2}} G_{1}\left(k_{1}\right) G_{2}\left(k_{2}-\right.$ $\left.k_{1}\right) \cdots G_{n-1}\left(k_{n-1}-k_{n-2}\right) G_{n}\left(k-k_{n-1}\right)$.

Theorem 7 (Arikoglu and Ozkol, 2008; Fakharzadeh et al., 2015): If $f(x)=\int_{x_{0}}^{x} g(t) d t$ then, $F(k)=$ $\frac{G(k-1)}{k}$, where $k \geq 1$. 
Theorem 8 (Arikoglu and Ozkol, 2008; Fakharzadeh et al., 2015): If $f(x)=\int_{x_{0}}^{x} \int_{x_{0}}^{x_{n-1}} \cdots \int_{x_{0}}^{x_{3}} \int_{x_{0}}^{x_{2}} \int_{x_{0}}^{x_{1}} g(t) d t d x_{1} d x_{2} d x_{3} \cdots d x_{n-1}$ is given then, $F(k)=\frac{(k-n) !}{k !} G(k-n)$, for $k \geq n$.

Theorem 9 (Arikoglu and Ozkol, 2008; Fakharzadeh et al., 2015): If $f(x)=g(x) \int_{x_{0}}^{x} h(t) d t$ then, $F(k)=$ $\sum_{k_{1}=1}^{k} \frac{1}{k_{1}} G\left(k-k_{1}\right) H\left(k_{1}-1\right)$, where $k \geq 1$.

Theorem 10 (Arikoglu and Ozkol, 2008; Fakharzadeh et al., 2015): If $f(x)=\int_{x_{0}}^{x} g_{1}(t) g_{2}(t) d t$ then $F(k)=\frac{1}{k} \sum_{k_{1}=0}^{k} G_{1}\left(k_{1}\right) G_{2}\left(k-k_{1}-1\right)$, where $k \geq 1$.

Theorem 11 (Arikoglu and Ozkol, 2008; Fakharzadeh et al., 2015): If $f(x)=\int_{x_{0}}^{x} g_{1}(t) g_{2}(t) \cdots g_{n-1}(t) g_{n}(t) d t$ then $F(k)=\frac{1}{k} \sum_{k_{n-1=0}}^{k-1} \sum_{k_{n-2}=0}^{k_{n-1}} \cdots \sum_{k_{2}=0}^{k_{3}} \sum_{k_{1}=0}^{k_{2}} G_{1}\left(k_{1}\right) G_{2}\left(k_{2}-\right.$ $\left.k_{1}\right) \cdots G_{n-1}\left(k_{n-1}-k_{n-2}\right) G_{n}\left(k-k_{n-1}-1\right)$.

Theorem 12 (Arikoglu and Ozkol, 2008; Fakharzadeh et al., 2015): If $f(x)=\left[h_{1}(x) h_{2}(x) \cdots h_{n-1}(x) h_{n}(x)\right] \int_{x_{0}}^{x} g_{1}(t) g_{2}(t) \cdots g_{m-1}(t) g_{m}(t) d t$ then $F(k)=\sum_{k_{m+n-1=1}}^{k} \sum_{k_{m+n-2}=1}^{k_{m+n-1}} \cdots \sum_{k_{2}=1}^{k_{3}} \sum_{k_{1}=1}^{k_{2}} \frac{1}{k_{m}} G_{1}\left(k_{1}-1\right) G_{2}\left(k_{2}-k_{1}\right) \cdots G_{m-1}\left(k_{m-1}-k_{m-2}\right) G_{m}\left(k_{m}-\right.$ $\left.k_{m-1}\right) \times H_{1}\left(k_{m+1}-k_{m}\right) H_{2}\left(k_{m+2}-k_{m+1}\right) \cdots H_{n-1}\left(k_{n+m-1}-k_{n+m-2}\right) H_{n}\left(k-k_{m+n-1}\right)$.

\section{Numerical Examples}

In this section, some examples are given for the application of the Differential Transformation Method (DTM) to obtain approximations to the expected values and variances of random Volterra integral equations. Each example contains random integral equations with different probability distributions.

Example 4.1 Consider the random Volterra integral equation

$$
u(x)=B+A x-\frac{A x^{3}}{3 !}+\int_{0}^{x}(x-t) \mathrm{u}(t) d t, u(0)=B
$$

where $A$ and $B$ are random variables with uniform distribution within the interval (Chiles and Delfier, 1999; Cortes et al.,2009), i.e. $A, B \sim U(\alpha=1, \beta=2)$ with the parameters $\alpha=1$ and $\beta=2$. Using DTM for the equation (6), we obtain

$$
\begin{aligned}
U(k)=B \delta(k)+ & A \delta(k-1)-\frac{A}{3 !} \delta(k-3)+\sum_{k_{1}=1}^{k} \frac{\delta\left(k-k_{1}-1\right) U\left(k_{1}-1\right)}{k_{1}} \\
& -\sum_{k_{1}=0}^{k-1} \frac{\delta\left(k_{1}-1\right) U\left(k-k_{1}-1\right)}{k}, k \geq 1
\end{aligned}
$$

Using (7) with the inverse transformation (Theorems 10 and 11),

$$
\begin{gathered}
U(0)=B, U(1)=A, U(2)=B / 2 !, U(3)=0, U(4)=\frac{B}{4 !}, U(5)=0, U(6)=\frac{B}{6 !}, \\
U(7)=0, \cdots
\end{gathered}
$$

and hence, the solution is given as

$$
\begin{gathered}
u(x)=\sum_{k=0}^{\infty} U(k) x^{k}=A x+B+\frac{B x^{2}}{2 !}+\frac{B x^{4}}{4 !}+\frac{B x^{6}}{6 !}+\cdots=A x+B\left[1+\frac{x^{2}}{2 !}+\frac{x^{4}}{4 !}+\frac{x^{6}}{6 !}+\cdots\right] \\
=A x+B \cosh (x) .
\end{gathered}
$$


Numerical characteristics of the approximate solutions of the random Volterra integral equation found with random DTM are obtained through the following calculations (Fakharzadeh et al., 2015; Golmankhaneh et al., 2013)

$$
\begin{aligned}
& E[u(x)]=\sum_{k=0}^{n} E[U(k)] x^{k}, \\
& \operatorname{Var}[u(x)]=\sum_{i=0}^{n} \sum_{j=0}^{n} \operatorname{cov}(U(i), U(j)) x^{i+j} .
\end{aligned}
$$

Higher moments of the random variables are needed for the calculation of the approximate expectation and variances. The moment generating function of a uniformly distributed random variable $X$, i.e. $X \sim U(\alpha, \beta)$, is given as (Feller, 1968):

$$
M_{X}(t)=E\left[e^{t X}\right]=\frac{e^{\beta t}-e^{\alpha t}}{(\beta-\alpha) t}
$$

Hence, the first two moments of $X$ are

$$
E[X]=\frac{\alpha+\beta}{2}, \operatorname{Var}[X]=\frac{(\alpha-\beta)^{2}}{12} .
$$

Using these and the independency of random variables $(E[X Y]=E[X] E[Y]$ for independent random variables $X$ and $Y$ ), the expectation of the solution is obtained as:

$$
\begin{gathered}
E(u(x))=\sum_{k=0}^{\infty} E(U(k)) x^{k}=E(A) x+E(B)\left[x-\frac{x^{3}}{3 !}+\frac{x^{5}}{5 !}-\frac{x^{7}}{7 !}+\cdots\right] \\
=E(A) x+E(B) \cosh (x) .
\end{gathered}
$$

Similarly, the variance becomes

$$
\operatorname{Var}(u(x))=E\left(u(x)^{2}\right)-E(u(x))^{2}=\operatorname{Var}(A) x^{2}+\operatorname{Var}(B) \cosh (x)^{2} .
$$

Since $A, B \sim U(\alpha=1, \beta=2)$ with $\alpha=1$ and $\beta=2$, we get:

$$
E(u(x))=\frac{3}{2} x+\frac{3}{2} \cosh (x), \operatorname{Var}(u(x))=\frac{1}{12} x^{2}+\frac{1}{12} \cosh (x)^{2} .
$$

The results are shown in Figure 1.
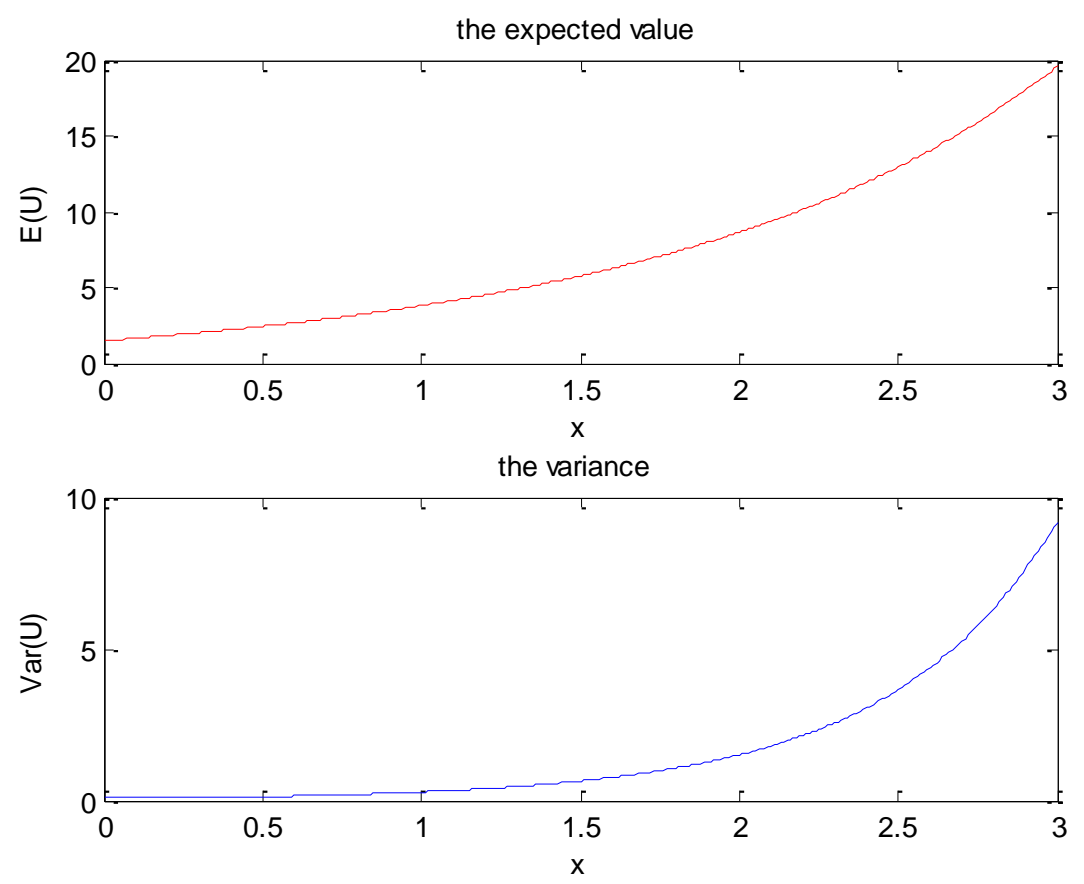

Figure 1. The expected value and variance of (6) obtained with random DTM. 
Example 4.2 Let us examine the random Volterra integral equation

$$
u(x)=(A+C) x+\frac{A x^{3}}{3 !}-\int_{0}^{x}(t-x) \mathrm{u}(t) d t, u(0)=0
$$

where $A$ and $C$ are random variables with Beta distribution such that the shape parameters are given as $\alpha=3$ and $\beta=2$, i.e. $A, C \sim B(\alpha=3, \beta=2)$. For the application of DTM, (12) is transformed as:

$$
\begin{gathered}
U(k)=(A+C) \delta(k-1)+\frac{A \delta(k-3)}{3 !}-\sum_{k_{1}=1}^{k} \frac{\delta\left(k-k_{1}-1\right) U\left(k_{1}-1\right)}{k_{1}} \\
+\sum_{k_{1}=0}^{k-1} \frac{\delta\left(k_{1}-1\right) U\left(k-k_{1}-1\right)}{k} .
\end{gathered}
$$

Theorems 11 and 12 are used and for $k \geq 1$, the inverse transformation is obtained.

$$
\begin{gathered}
U(0)=0, U(1)=A+C, U(2)=0, U(3)=-\frac{C}{3 !}, U(4)=0, U(5)=\frac{C}{5 !}, U(6)=0, \\
U(7)=-\frac{C}{7 !}, \cdots
\end{gathered}
$$

The solution becomes:

$$
\begin{aligned}
u(x)=\sum_{k=0}^{\infty} U(k) x^{k}=(A+C) x-\frac{C x^{3}}{3 !}+\frac{C x^{5}}{5 !}-\frac{C x^{7}}{7 !}+\cdots \\
=A x+C\left[x-\frac{x^{3}}{3 !}+\frac{x^{5}}{5 !}-\frac{x^{7}}{7 !}+\cdots\right]=A x+C \sin (x) .
\end{aligned}
$$

The moment generating function of a Beta distributed random variable is given as (Feller, 1968):

$$
M_{X}(t)=E\left[e^{t X}\right]=1+\sum_{k=1}^{\infty}\left(\prod_{r=0}^{k-1} \frac{\alpha+r}{\alpha+\beta+r}\right) t^{k} / k ! .
$$

Thus, the expectation, second moment and the variance of a Beta distributed random variable are

$$
E[X]=\frac{\alpha}{\alpha+\beta}, E\left[X^{2}\right]=\frac{\alpha(\alpha+1)}{(\alpha+\beta+1)(\alpha+\beta)} \text { and } \operatorname{Var}[X]=\frac{\alpha \beta}{(\alpha+\beta)^{2}(\alpha+\beta+1)} .
$$

These formulas and the independency of the random variables gives:

$$
\begin{gathered}
E(u(x))=\sum_{k=0}^{\infty} E(U(k)) x^{k}=E(A) x+E(C)\left[x-\frac{x^{3}}{3 !}+\frac{x^{5}}{5 !}-\frac{x^{7}}{7 !}+\cdots\right] \\
=E(A) x+E(C) \sin (x)
\end{gathered}
$$

Similarly, the variance becomes:

$$
\operatorname{Var}(u(x))=E\left(u(x)^{2}\right)-E(u(x))^{2}=\operatorname{Var}(A) x^{2}+\operatorname{Var}(C) \sin ^{2}(x) .
$$

For $\alpha=3$ and $\beta=2$, we get:

$$
E(u(x))=\frac{5}{2} x+\frac{5}{2} \sin (x), \quad \operatorname{Var}(u(x))=\frac{1}{25} x^{2}+\frac{1}{25} \sin ^{2}(x) .
$$

The results are shown in Figure 2. 

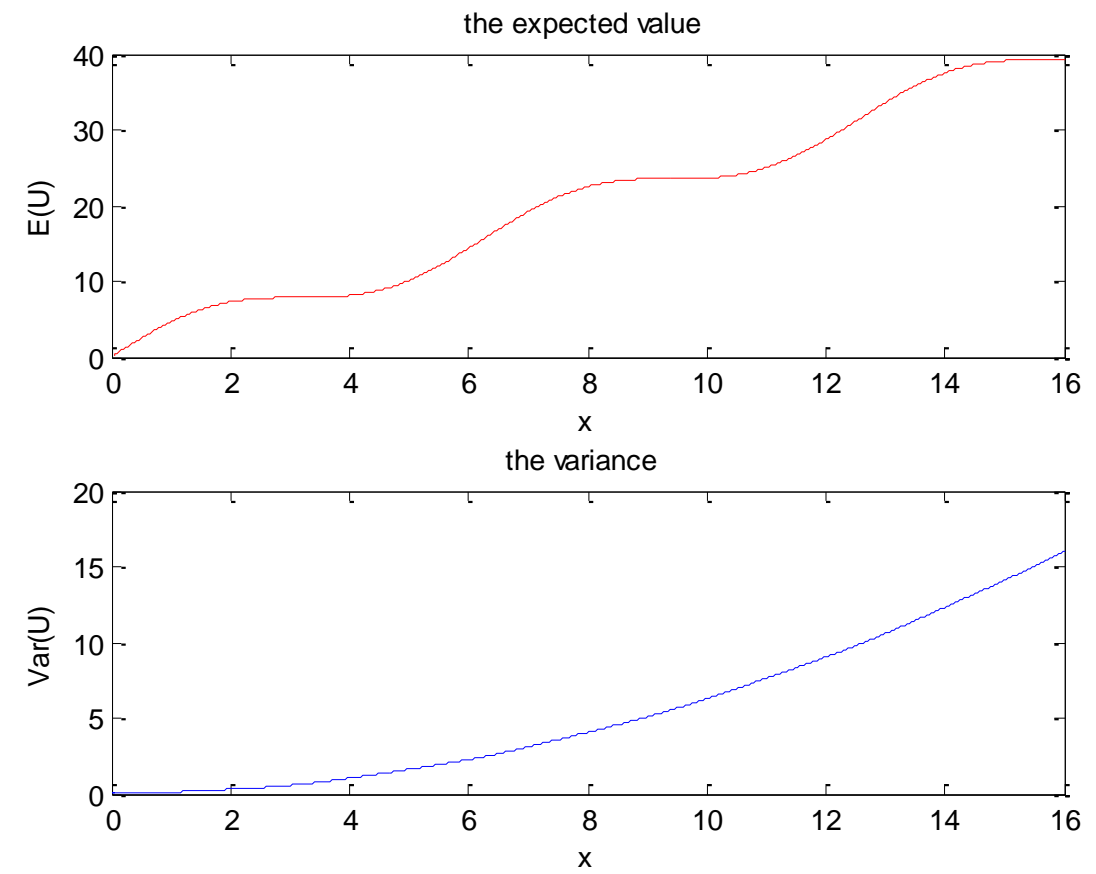

Figure 2. The expected value and variance of (12) obtained with random DTM.

Example 4.3 Consider the random Volterra integral equation

$$
u(x)=A+A x+\int_{0}^{x}(t-x) \mathrm{u}(t) d t, u(0)=A
$$

where $A$ is a normal (Gaussian) random variables with mean and standard deviation $\mu=4$ and $\sigma=3$, i.e. $A \sim N\left(\mu=4, \sigma^{2}=9\right)$. Application of DTM requires the transformation of (18) as (Theorems 5, 10, 11):

$$
U(k)=A \delta(k)+A \delta(k-1)+\sum_{k_{1}=1}^{k} \frac{\delta\left(k-k_{1}-1\right) U\left(k_{1}-1\right)}{k_{1}}-\sum_{k_{1}=0}^{k-1} \frac{\delta\left(k_{1}-1\right) U\left(k-k_{1}-1\right)}{k} .
$$

Using the inverse transformations to get the solutions, we find

$$
\begin{gathered}
U(0)=A, U(1)=\frac{A}{1 !}, U(2)=\frac{A}{2 !}, U(3)=\frac{A}{3 !}, U(4)=\frac{A}{4 !}, U(5)=\frac{A}{5 !}, U(6)=\frac{A}{6 !}, \\
U(7)=A / 7 !, \cdots
\end{gathered}
$$

and

$$
\begin{array}{r}
u(x)=\sum_{k=0}^{\infty} U(k) x^{k}=A+A x+\frac{A x^{2}}{2 !}+\frac{A x^{3}}{3 !}+\frac{A x^{4}}{4 !}+\frac{A x^{5}}{5 !}+\cdots \\
=A\left[1+x+\frac{x^{2}}{2 !}+\frac{x^{3}}{3 !}+\frac{x^{4}}{4 !}+\frac{x^{5}}{5 !}+\cdots\right]=A e^{x} .
\end{array}
$$

Since the moment generating function (MGF) of a Gaussian random variable $X \sim N\left(\mu, \sigma^{2}\right.$ ) is (Feller, 1968):

$$
M_{X}(t)=E\left[e^{t X}\right]=e^{\left(\mu t+\frac{1}{2} \sigma^{2} t^{2}\right)},
$$

We find the first two moments and the variance as

$$
E[X]=\mu, E\left[X^{2}\right]=\mu^{2}+\sigma^{2}, \operatorname{Var}[X]=\sigma^{2} .
$$

Using these results, the expectation becomes:

$$
E(u(x))=\sum_{k=0}^{\infty} E(U(k)) x^{k}=E(A)\left[1+x+\frac{x^{2}}{2 !}+\frac{x^{3}}{3 !}+\frac{x^{4}}{4 !}+\frac{x^{5}}{5 !}+\cdots\right]=E(A) e^{x},
$$

and the variance:

$$
\begin{aligned}
\operatorname{Var}(u(x))= & E\left(u(x)^{2}\right)-E(u(x))^{2}=\operatorname{Var}(A)\left[1+x+\frac{x^{2}}{2 !}+\frac{x^{3}}{3 !}+\frac{x^{4}}{4 !}+\frac{x^{5}}{5 !}+\cdots\right]^{2} \\
= & \operatorname{Var}(A) e^{2 x}
\end{aligned}
$$


For $\mu=4$ and $\sigma=3$, we get:

$$
E(u(x))=4 e^{x}, \operatorname{Var}(u(x))=9 e^{2 x} .
$$

The results are shown in Figure 3.

Example 4.4 Consider the random Volterra integro differential equation

$$
\begin{aligned}
& u^{\prime}(x)=-\frac{B}{2} e^{-2 x}+A+\frac{B}{2}-A e^{-x}-B e^{-x}-\int_{0}^{x} e^{-t} u(t) d t, \\
& u(0)=A+B, u^{\prime}(0)=-B
\end{aligned}
$$

where $A$ and $B$ are Gamma distributed random variables such that the shape and scale parameters are given as $\alpha=4$ and $\beta=2$, hence $A, B \sim G(\alpha=4, \beta=2)$.

Transforming (24), we get (Theorems 10, 11):

$$
\begin{aligned}
(k+1) U(k+1) & \\
= & -\frac{\frac{B}{2}(-2)^{k}}{k !}+A \delta(k)+\frac{B}{2} \delta(k)-\frac{A(-1)^{k}}{k !}-\frac{B(-1)^{k}}{k !} \\
& -\sum_{k_{1}=0}^{k-1} \frac{(-1)^{k_{1}} U\left(k-k_{1}-1\right)}{k_{1} ! k} .
\end{aligned}
$$

For $k \geq 1$, the inverse transformations and the solution are found.

and

$$
\begin{gathered}
U(0)=A+B, U(1)=-\frac{B}{1 !}, U(2)=\frac{B}{2 !}, U(3)=-\frac{B}{3 !}, U(4)=\frac{B}{4 !}, U(5)=-\frac{B}{5 !}, \\
U(6)=\frac{B}{6 !}, U(7)=-\frac{B}{7 !}, \cdots
\end{gathered}
$$
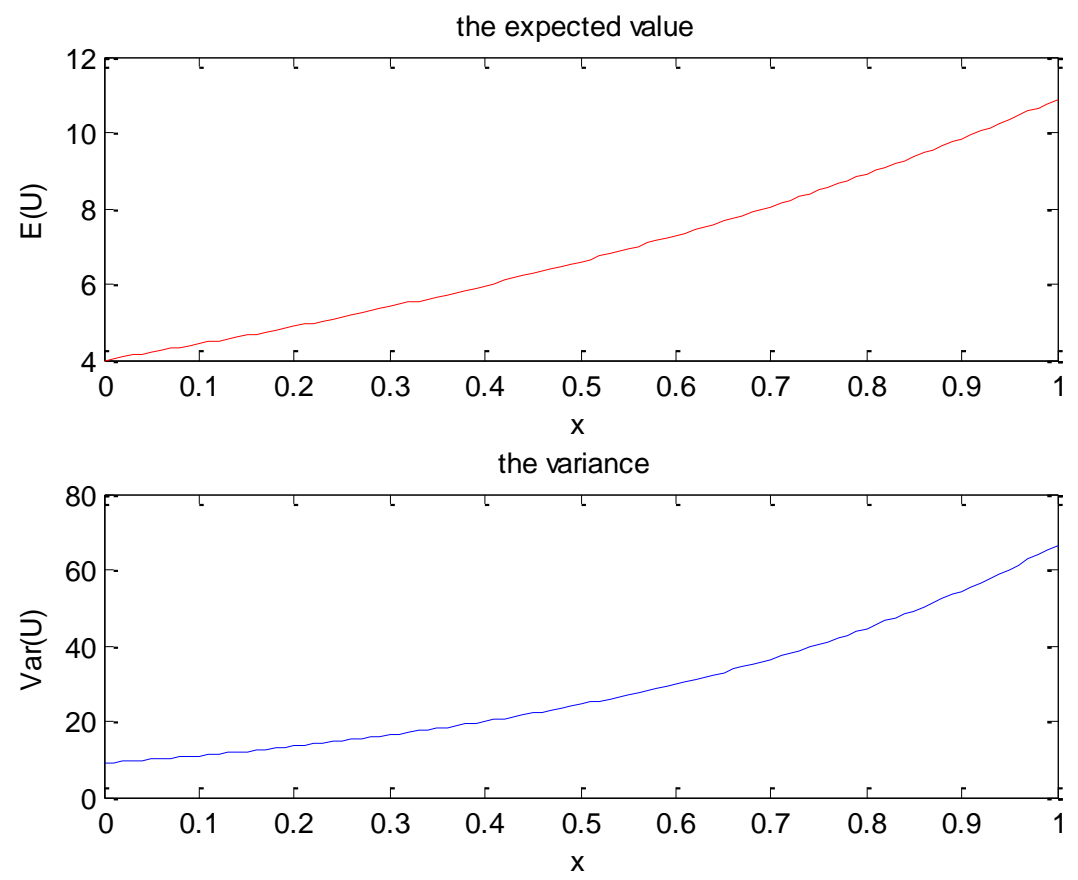

Figure 3. The expected value and variance of (18) obtained with random DTM.

$$
\begin{aligned}
u(x)=\sum_{k=0}^{\infty} U(k) x^{k}=A+B-B x+\frac{B x^{2}}{2 !}-\frac{B x^{3}}{3 !}+\frac{B x^{4}}{4 !}-\frac{B x^{5}}{5 !}+\cdots \\
=A+B\left[1-x+\frac{x^{2}}{2 !}-\frac{x^{3}}{3 !}+\frac{x^{4}}{4 !}-\frac{x^{5}}{5 !}+\cdots\right]=A+B e^{-x}
\end{aligned}
$$


The MGF of a Gamma distributed random variable $X$ is given as (Feller, 1968)

$$
M_{X}(t)=E\left[e^{t X}\right]=\frac{1}{(1-\beta t)^{\alpha}} .
$$

Thus, the mean and variance of $X \sim G(\alpha, \beta)$ are:

$$
E[X]=\alpha \beta, \operatorname{Var}[X]=\alpha \beta^{2} .
$$

Using these and the independency of the random variables, we get:

$$
\begin{gathered}
E(u(x))=\sum_{k=0}^{\infty} E(U(k)) x^{k}=E(A)+E(B)\left[1-x+\frac{x^{2}}{2 !}-\frac{x^{3}}{3 !}+\frac{x^{4}}{4 !}-\frac{x^{5}}{5 !}+\cdots\right] \\
=E(A)+E(B) e^{-x}
\end{gathered}
$$

and

$$
\begin{aligned}
\operatorname{Var}(u(x))=E & \left(u(x)^{2}\right)-E(u(x))^{2} \\
& =\operatorname{Var}(A)+\operatorname{Var}(B)\left[1-x+\frac{x^{2}}{2 !}-\frac{x^{3}}{3 !}+\frac{x^{4}}{4 !}-\frac{x^{5}}{5 !}+\cdots\right]^{2} \\
& =\operatorname{Var}(A)+\operatorname{Var}(B) e^{-2 x} .
\end{aligned}
$$

For $\alpha=4$ and $\beta=2$, i.e. $A, B \sim G(\alpha=4, \beta=2)$, we find:

$$
E(u(x))=8+8 e^{-x}, \operatorname{Var}(u(x))=16+16 e^{-2 x} .
$$

The results are shown in Figure 4.
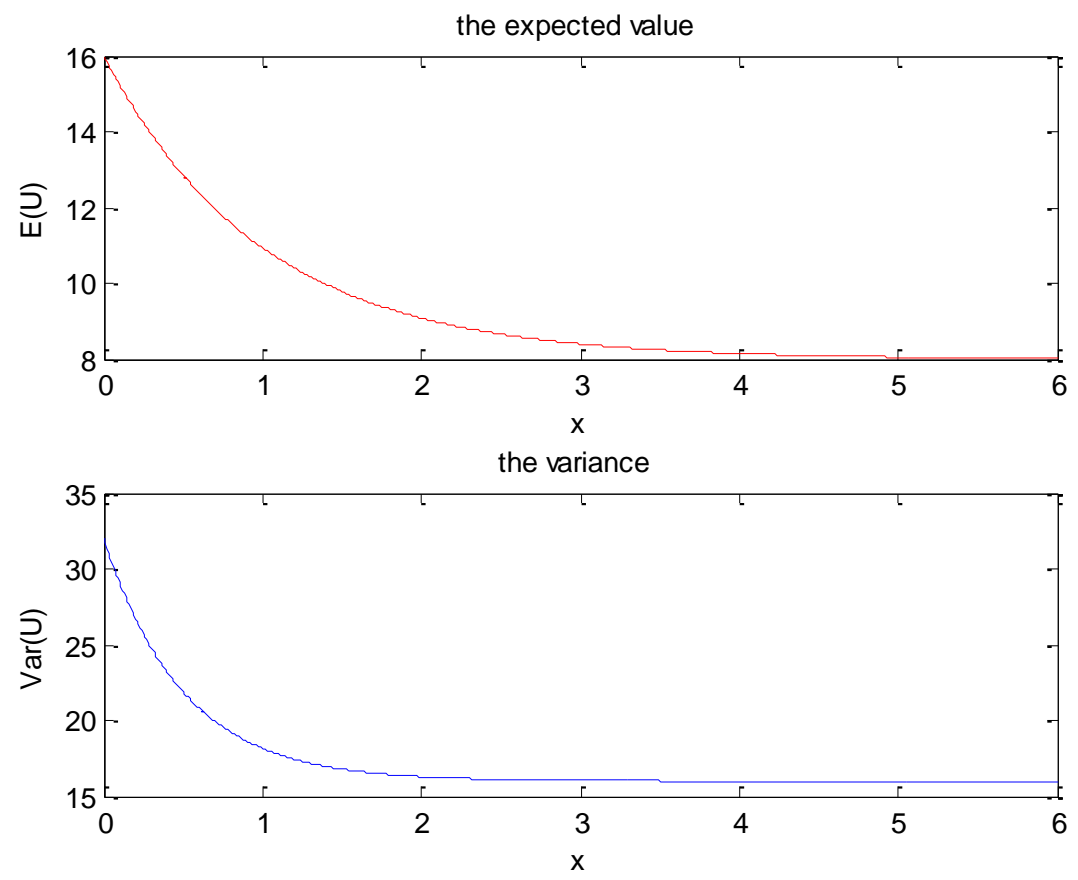

Figure 4. The expected value and variance of (24) obtained with random DTM.

Example 4.5 Consider the nonlinear random Volterra integro differential equation

$$
\begin{aligned}
u^{\prime}(x)=\frac{A-B}{2} & +B \cos (x)-A \sin (x)-\frac{A+B}{2} e^{x} \sin (x)+\frac{B-A}{2} e^{x} \cos (x) \\
& +\int_{0}^{x}\left(e^{t} u(t)\right) d t, u(0)=0 .
\end{aligned}
$$

where $A$ and $B$ are geometrically distributed random variables such that $p=\frac{1}{4}$ and $q=3 / 4$, i.e. $A, B \sim G(p=$ $\frac{1}{4}, q=\frac{3}{4}$ ). Transformation of (30) for DTM gives (Theorems 5, 10, 11): 


$$
\begin{aligned}
(k+1) U(k+1) & \\
= & \frac{A-B}{2} \delta(k)+\frac{B}{k !} \cos \left(\frac{k \pi}{2}\right)-\frac{A}{k !} \sin \left(\frac{k \pi}{2}\right)-\frac{A+B}{2} \sum_{k_{1}=0}^{k} \frac{\sin \left(\frac{k_{1} \pi}{2}\right)}{k_{1} !\left(k-k_{1}\right) !} \\
& +\frac{B-A}{2} \sum_{k_{1}=0}^{k} \frac{\cos \left(\frac{k_{1} \pi}{2}\right)}{k_{1} !\left(k-k_{1}\right) !}-2 \sum_{k_{1}=0}^{k-1} \frac{U\left(k-k_{1}-1\right)}{k k_{1} !}
\end{aligned}
$$

for $k \geq 1$. Inverse transformations and the solution are obtained through (31) as:

$$
\begin{aligned}
U(0)=A, U(1) & =B, U(2)=-\frac{A}{2 !}, U(3)=-\frac{B}{3 !}, U(4)=\frac{A}{4 !}, U(5)=\frac{B}{5 !}, U(6)=-\frac{A}{6 !}, U(7) \\
& =-B / 7 !, U(8)=A / 8 !, U(9)=B / 9 !, \cdots
\end{aligned}
$$

And

$$
\begin{aligned}
u(x)=\sum_{k=0}^{\infty} U(k) & x^{k}=A-\frac{A x^{2}}{2 !}+\frac{A x^{4}}{4 !}-\frac{A x^{6}}{6 !}+\frac{A x^{8}}{8 !}-\cdots+B x-\frac{B x^{3}}{3 !}+\frac{B x^{5}}{5 !}-\frac{B x^{7}}{7 !} \\
+ & \frac{B x^{9}}{9 !} \ldots=A\left[1-\frac{x^{2}}{2 !}+\frac{x^{4}}{4 !}-\frac{x^{6}}{6 !}+\cdots\right]+B\left[x-\frac{x^{3}}{3 !}+\frac{x^{5}}{5 !}-\frac{x^{7}}{7 !}+\cdots\right] \\
= & A \cos (x)+B \sin (x) .
\end{aligned}
$$

The MGF of a Geometrically distributed $X \sim G(p, q)$ is given as (Feller, 1968):

$$
M_{X}(t)=E\left[e^{t X}\right]=\frac{p e^{t}}{1-q e^{t}} .
$$

Thus, the expectation and the variance are:

$$
E[X]=\frac{1}{p}, \operatorname{Var}[X]=\frac{q}{p^{2}} .
$$

Using these and the independency of the random variables, we get

$$
\begin{aligned}
E(u(x))=\sum_{k=0}^{\infty} & E(U(k)) x^{k} \\
& =E(A)\left[1-\frac{x^{2}}{2 !}+\frac{x^{4}}{4 !}-\frac{x^{6}}{6 !}+\cdots\right]+E(B)\left[x-\frac{x^{3}}{3 !}+\frac{x^{5}}{5 !}-\frac{x^{7}}{7 !}+\cdots\right] \\
& =E(A) \cos (x)+E(B) \sin (x)
\end{aligned}
$$

and

$$
\begin{aligned}
\operatorname{Var}(u(x))=E & \left(u(x)^{2}\right)-E(u(x))^{2} \\
& =\operatorname{Var}(A)\left[1-\frac{x^{2}}{2 !}+\frac{x^{4}}{4 !}-\frac{x^{6}}{6 !}+\cdots\right]^{2}+\operatorname{Var}(B)\left[x-\frac{x^{3}}{3 !}+\frac{x^{5}}{5 !}-\frac{x^{7}}{7 !}+\cdots\right]^{2} \\
& =\operatorname{Var}(A) \cos ^{2}(x)+\operatorname{Var}(B) \sin ^{2}(x) .
\end{aligned}
$$

For $p=\frac{1}{4}$ and $q=\frac{3}{4}$, we get

$$
E(u(x))=4 \cos (x)+4 \sin (x), \operatorname{Var}(u(x))=12 \cos ^{2}(x)+12 \sin ^{2}(x)
$$

The results are shown in Figure 5. 

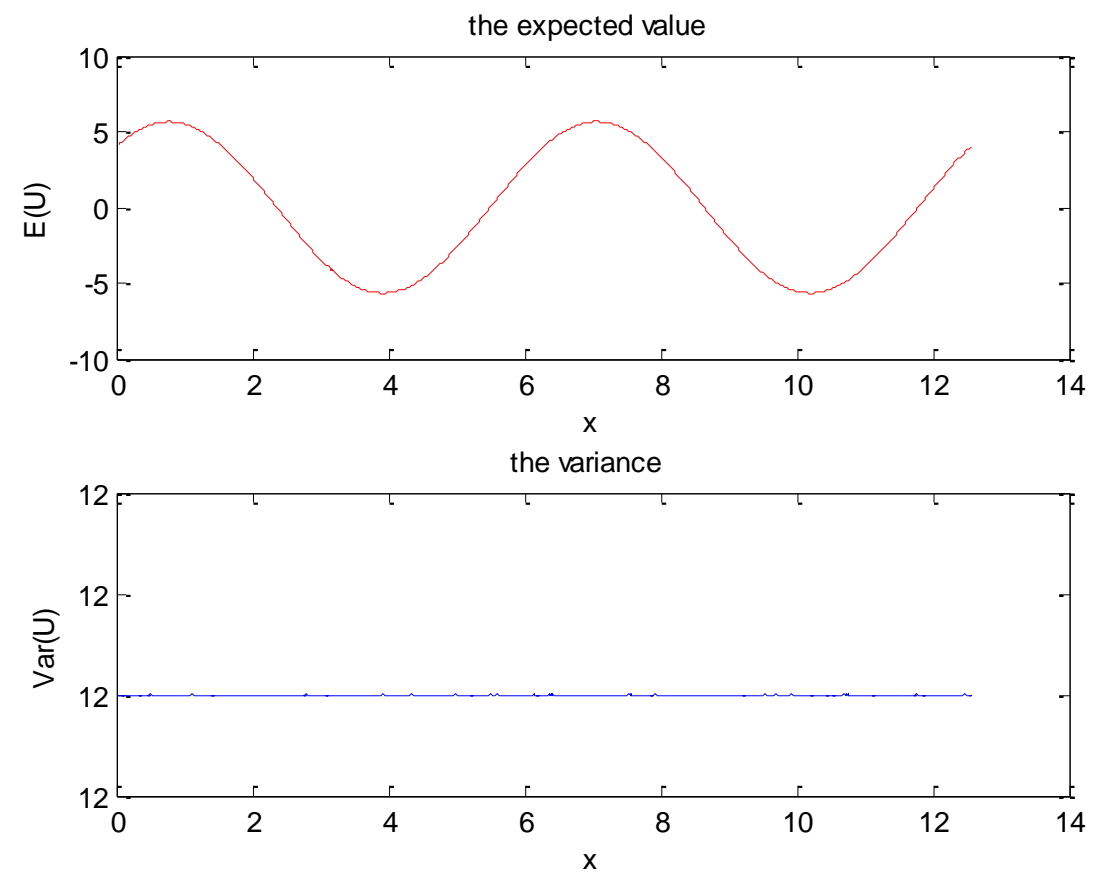

Figure 5. The expected value and variance of (30) obtained with random DTM.

\section{Conclusion}

In this study, the application of random Differential Transformation Method has been presented for the solutions of random Volterra integral equations. Volterra integral equations with random components having Uniform, Beta, Gaussian, Gamma and Geometric distributions are given as examples for the method. The expected values and the variances of the solutions are obtained and are also shown in graphs. Similar approaches can be seen for the Adomian Decomposition Method (Khudair et al., 2016), the Variational Iteration Method (Khudair et al., 2011), and the Homotopy Perturbation Method (Khalaf, 2011). We have shown that the Differential Transformation Method is an important tool for analysing random Volterra integral equations.

\section{References}

Aksoy, Y.,1983. İntegral Denklemler. Yildız Üniversitesi Yayınları, Cilt:1, Sayı:166.

Arikoglu, A. and Ozkol, I., 2005. Solution of boundary value problems for integro differential equations by using differential transform method. Appl Math Comput, 168, 1145-1158.

Arikoglu, A. and Ozkol, I., 2008. Solution of integral and integro-differential equation systems by using differential transform method. Comput Math Appl, 56, 2411-2417.
Calbo, G., Cortés, J.C. and Jódar, L., 2010. Mean Square Power Series Solution Of Random Linear Differential Equations. Computers And Mathematics With Applications, 59, 559-572.

Cherruault, Y., Saccomandi, G. and Some, B., 1993. New results for convergence of Adomian's method applied to integral equations, Mathl. Comput. Modelling, 16(2), 85-93.

Chiles, J. and Delfiner, P., 1999. Geostatistics: Modelling Spatial Uncertainty. John Wiley, New York.

Cortés, J.C., Jódar, L. and Villafuerte, L., 2007a. Mean Square Numerical Solution Of Random Differential Equations: Facts And Possibilities. Computers And Mathematics With Applications, 53, 1098-1106.

Cortés, J.C., Jódar, L. and Villafuerte, L., 2007b. Numerical Solution Of Random Differential Equations: A Mean Square Approach. Mathematical And Computer Modelling, 45, 757-765.

Cortes, J.C., Jodar, L. and Villafuerte, L., 2009. Random Linear-Quadratic Mathematical Models: Computing Explicit Solutions and Applications. Mathematics and Computers in Simulation, 79, 2076-2090.

Cortés, J.C., Jódar, L., Villafuerte, L. and Company, R., 2011. Numerical Solution Of Random Differential Models. Mathematical And Computer Modelling, 54, 1846-1851. 
Cortés, J.C., Jódar, L., Villanueva, R.-J. and Villafuerte, L., 2010. Mean Square Convergent Numerical Methods For Nonlinear Random Differential Equations. Lecture Notes İn Computer Science, 5890, 1-21.

Fakharzadeh, J., Hesamaeddini, E. and Soleimanivareki, M., 2015. Multi-step Stochastic Differential Transformation Method for solving Some Class of Random Differential Equations. Applied Mathematics in Engineering, Management and Technology, 3(3), 115-123.

Feller W., 1968. An Introduction to Probability Theory and Its Applications, volume 1, 3rd edition. New York: John Wiley \& Sons.

Golmankhaneh, A.K., Porghoveh, N.A. and Baleanu, D., 2013. Mean Square Solutions of SecondOrder Random Differential Equations by Using Homotopy Analysis Method. Romanian Reports in Physics, 65(2), 350-362.

Khalaf, S.L., 2011. Mean Square Solutions of SecondOrder Random Differential Equations by Using Homotopy Perturbation Method. International Mathematical Forum, 6, 2361-2370.

Khudair, A. R. , Haddad, S. A.M. and Khalaf, S. L., 2016. Mean Square Solutions of Second-Order Random Differential Equations by Using the Differential Transformation Method, Open Journal of Applied Sciences, 6, 287-297.

Khudair, A.R., Ameen, A.A. and Khalaf, S.L., 2011. Mean Square Solutions of Second-Order Random Differential Equations by Using Variational Iteration Method. Applied Mathematical Sciences, 5, 2505-2519.
Kythe, P. and Puri, P., 2011. Computational methods for linear integral equations. Springer Science \& Business Media.

Lovitt, W.V., 1950 Linear Integral Equations, Dover Publications, Inc.: New York.

Merdan, M., Anac, H., Bekiryazici, Z. and Kesemen, T. 2019. Solving of Some Random Partial Differential Equations by Using Differential Transformation Method and Laplace-Padé Method, Gumushane Universitesi Fen Bilimleri Enstitusu Dergisi, 9(1), 108-118.

Mohyud-Din, S. T., Yildirim, A. and Gülkanat, Y., 2010. Analytical solution of Volterra's population model, J. King Saud Univ. - Sci., 22(4), 247-250.

Soong, T.T., 1973. Random Differential Equations İn Science And Engineering. Academic Press, New York.

Villafuerte, L., Braumann, C.A., Cortés, J.C. and Jódar, L., 2010. Random Differential Operational Calculus: Theory And Applications. Computers \& Mathematics With Applications, 59, 115-125.

Wazwaz, A. M., 1999. Analytical approximations and Padé approximants for Volterra's population model, Appl. Math. Comput., 100(1), 13-25.

Wazwaz, A. M., 2011. Linear and nonlinear integral equations (Vol. 639). Heidelberg: Springer.

Wazwaz, A.M., 1997. A First Course in Integral Equations, World Scientific: Singapore. 